\title{
Research Topics on Railway Vehicle Dynamics
} - A Literature Survey Focusing on the Works from Japan -

\author{
Takahiro Tomioka ${ }^{\mathrm{a}, *}$ \\ ${ }^{a}$ Department of Mechanical Engineering, Faculty of Systems, Science and Technology, Akita Prefectural University. \\ Email:tomioka@akita-pu.ac.jp
}

\begin{abstract}
Engineering research subjects relating railway vehicle dynamics are described as a literature survey in this paper. Research works concerning to the motion of wheelset; pantograph-catenary interaction; aerodynamic relating problems on the vehicle; and application of control techniques are introduced firstly as the most distinctive subjects of railway vehicle dynamics. The topics on safety assessment and ride comfort evaluation are also dealt with since those are important research area in railway dynamics as public transportation system. The subject concerning to carbody elastic vibration, which is important relating to ride comfort, is also described. The effect of passengers on the elastic vibration of carbody has been introduced as the interesting (and something surprising) topic. The focuses in the literature survey are particularly on the research works from Japan, in this paper.
\end{abstract}

Keywords: Dynamics of railway vehicles; mechanical engineering; ride comfort; safety assessment; vibration problems

\section{Introduction}

As widely known, railway system is one of the origin of mechanical engineering; the first president of the world's oldest society of mechanical engineers (Institution of Mechanical Engineers: IMechE), which was founded in 1847 in Birmingham, UK, was George Stephenson who is famous as the Father of Railways. (And the second president of IMechE was Robert Stephenson; the son of George and he was also a railway engineer.) It is obvious that railway was one of the most important object for study in mechanical engineering at that time. Many engineering subjects e.g. tribology, fatigue of metals, fracture mechanics, heat treatment of metals, development of materials like steels and aluminum alloys, were raised or developed together with the advancement of railways. Problems relating dynamics such as vibrations and sound have also been closely connected to railways. And even now, railway still remains one of the most interesting subjects of research in engineering. This paper intends to introduce the engineering research topics relating railway vehicles from the view of dynamics as a literature survey.

\footnotetext{
${ }^{*}$ Corresponding author. Tel.: +81-184-27-2131

84-4, Tsuchiya-ebinokuchi,

Yurihonjo, Akita, Japan, 015-0055
}

About the dynamics of railway vehicles, a lot of research works have been carried out in Europe for a long time, and several good books are available (e.g. [1, 2]). On the other hand, there are also a long history in this field in Japan; a number of great achievements were made from Japan and the Shinkansen is one of the fine fruits of those researches. However, in the author's view, such research activities are lesser-known versus their importance. One reason of this is considered that many of them are written in Japanese; though, not a few works are published in English. This paper focuses the research works from Japan.

\section{Characteristic Dynamics in Railway Vehicles}

\subsection{Wheelset motion}

One of major features of railway vehicles is using wheelsets with conical wheels. A wheelset is a set of a pair of wheels and an axle; the wheels are tightly pressed into a common axle, so the right and left wheels rotate with a common angular velocity. Figure 1 shows the schematic illustration of a wheelset. Each wheel's tread has a slope such as the radius of the wheel becomes smaller to the outer side of the axle. It is called coning, conicity or wheel tread gradient. The typical conicity is, for instance, $1 / 20$ or $1 / 40$. Due to the conicity of the wheels, there are some 


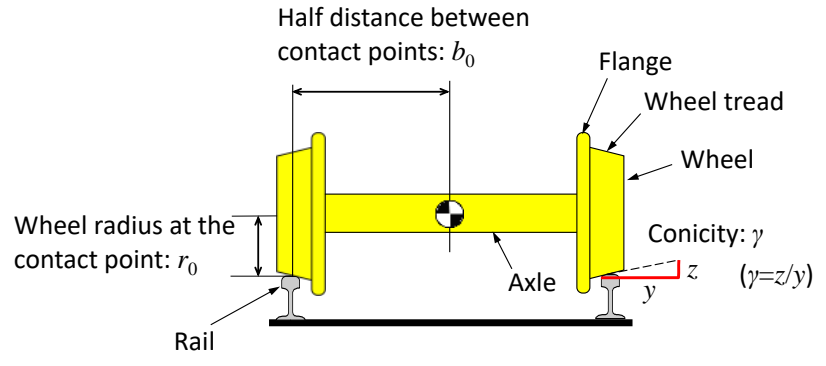

Figure 1. Wheelset of railway vehicles

characteristic dynamics such as self-steering ability and hunting motion. Leaving their detailed theoretical treatments up to the published books [1,2], some results are described here as follows.

The self-steering ability is the function to return automatically to the center of the track when a wheelset moves to one side of the track without using intentional steering manipulation. Railway vehicles don't have steering wheels like automobiles: the self-steering ability is produced by the difference of the radii of both side wheels in a wheelset. As shown in Fig. 2(a) when a wheelset goes into curve section, the wheelset moves to the outer side of the curve and the wheel on the outer rail contacts with the rail head in larger radius. Since both wheels rotate with the same angular velocity, the outer side wheel runs faster than the other wheel, and thus the wheelset can pass the curve smoothly. When a wheelset running on straight section is displaced to one side of the track as shown in Fig. 2(b), the wheel of the displaced side contacts with the rail head in larger radius and the wheel runs faster than the other one; and the wheelset returns to the center of the track. It should be noted that the flanges shown in Fig. 1 are not usually needed in order to pass curves or return to the track center. The flanges are necessary in case such as passing sharper curves or prevent derailment caused by extraordinary lateral force.

The trajectory of the center of a wheelset passing a curve purely by the self-steering ability is called pure rolling line. The wheelset running on the pure rolling line don't generate
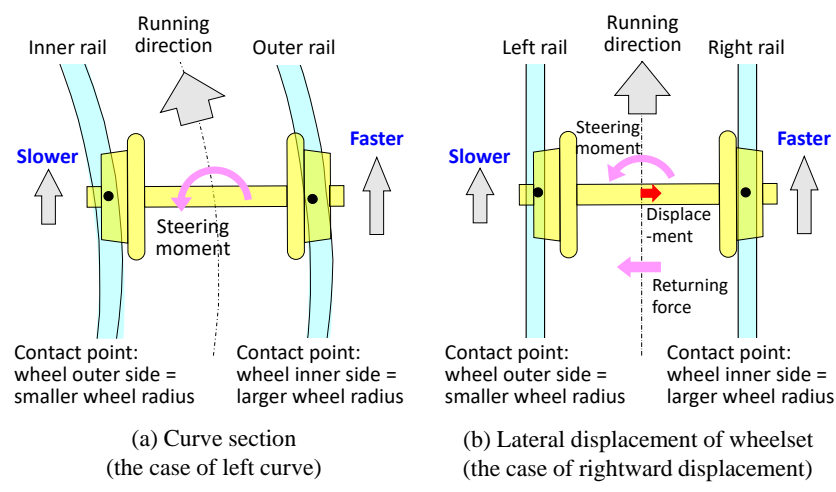

Figure 2. Self-steering ability of wheelsets longitudinal force (longitudinal creep force). The lateral displacement $y_{0}$ to sustain pure rolling during passing a curve with radius $R$ can be expressed using conicity $\gamma$ (see Fig. 1) and the radius of the wheel in the neutral position $r_{0}$ and the half distance between rails $b_{0}$ as,

$$
y_{0}=\frac{b_{0} r_{0}}{R \gamma}
$$

This formula is obtained by the simple geometric relationship between parameters shown in Fig. 3 .

According to the self-steering ability, if pure rolling is maintained, a wheelset can move back toward the center of the track when it displaces slightly to one side of the track. However, during the regaining motion, the wheelset overshoots the center and this causes oscillatory motion called kinematic hunting. The trajectory of the wheelset kinematic hunting can be expressed a sinusoidal curve as shown in Fig. 4 and its wavelength $S_{1}$ can be described as,

$$
S_{1}=2 \pi \sqrt{\frac{b_{0} r_{0}}{\gamma}}
$$

Although the kinematic hunting motion of wheelsets is known since early times [3], the fact that the kinematic hunting is an unstable oscillation and elastically supported two-axled bogie also have similar unstable hunting

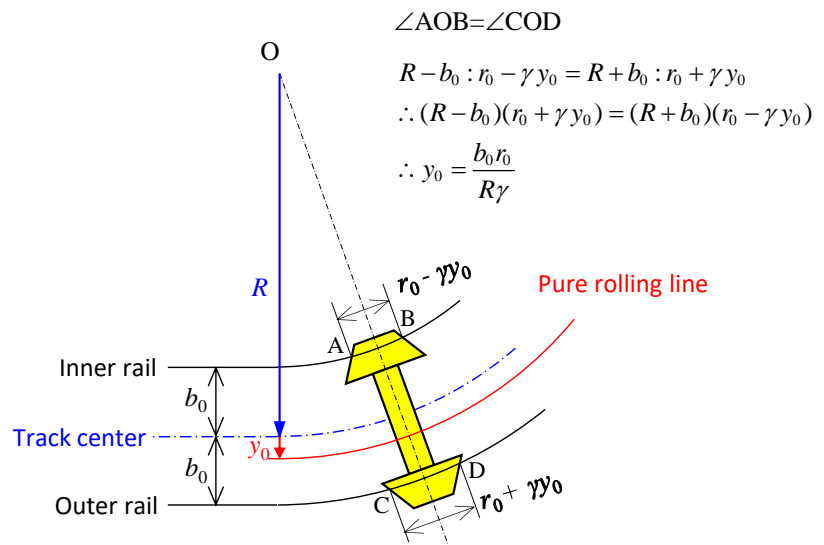

Figure 3. Pure rolling of a wheelset in a curve

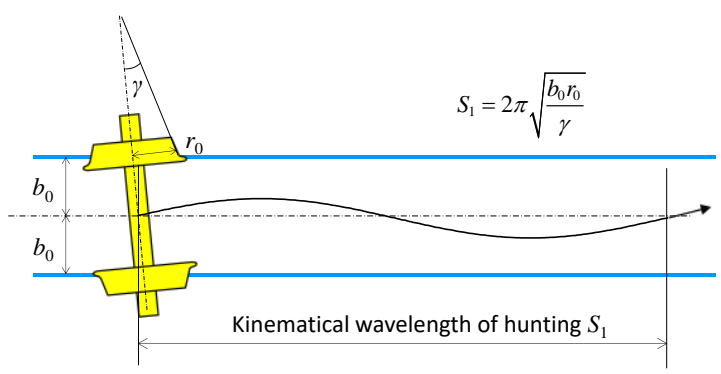

Figure 4. Kinematic hunting of a wheelset 
characteristics was firstly found out by Matsudaira shortly after World War II (WWII). He showed the hunting problem is one of the self-excited vibration and not occurred by external cause such as track irregularity. Thanks to the series of his research, design method of high-speed bogies was established and led to the realization of Shinkansen [4-8]. Unfortunately, since many of his research were published in Japanese, it is pointed out that "his research had little impact in the West" according to reference [2], however his works are widely known among researchers in the world in this field now.

The abilities of curving and hunting stability often require opposing properties on the bogie components. For instance, large conicity is advantageous to pass sharp curves, but leads to less hunting stability. To satisfy both of curving performance and running stability is one of important research topics in the railway vehicle dynamics.

Reducing the angle of attack (yaw angle of the wheelset relative to the track) in curve sections is a major strategy to improve curving performance. A number of theoretical and experimental studies have been carried out to realize bogies with small attack angle during curving. As one well known examples of these efforts, Suda [9] proved theoretically that unsymmetrical longitudinal supports of the two axles in a bogie can greatly reduce attack angle (zero attack angle can be realized, ideally) and the concept was adopted in the bogies of an EMU (electric multiple unit) limited express. Sato et al. [10] proposed a mechanically steering bogie with link mechanism and used in a DMU (diesel multiple unit) limited express. Recently, single axle steering bogie (one of the two axles in a bogie has steering mechanism) has been proposed and used in Tokyo Metro [11, 12].

\subsection{Dynamics of pantograph-catenary system}

As another characteristic topic concerning railway vehicle dynamics, interactions of the pantograph and catenary can be taken. A pantograph is a device to collect electricity from overhead contact line (called catenary here). The contact loss of pantograph and catenary causes problems not only collection loss of electricity but also severe damage of pantograph and catenary, acoustical and radio noise problems, etc. by the generation of arc. Therefore, the effort to reduce the contact loss is important.

The contact loss tends to occur as the vehicle speed becomes higher. After WWII, prior to the construction of Tokaido Shinkansen, speedup of trains of conventional lines were conducted and the dynamics of pantograph-catenary system was studied in detail. Shibata modelled the system as a mass supported by a periodically variable spring stiffness, which represents the effect of supporting span of catenary, with constant upward force. He showed its equation of motion can be expressed as a Mathieu's equation, and derived the critical velocity $V_{\mathrm{c}}$ to arise contact loss as [13],

$$
V_{\mathrm{c}}=\frac{l}{2 \pi} \sqrt{\frac{k_{0}}{M}} \sqrt{1-\frac{\varepsilon^{2}}{2}}
$$

where $l$ is the supporting span of the catenary, $k_{0}$ is average spring stiffness of the catenary, $M$ is mass of the pantograph and $\varepsilon$ is the parameter representing the variation of spring stiffness of catenary. This formula denotes increasing $M, \varepsilon$ and increasing $k_{0}$ are beneficial to improve the critical velocity $V_{\mathrm{c}}$. It was also suggested that applying damping in the pantograph is effective. These results were reflected in the design of pantographs for Shinkansen vehicles.

The pantograph-catenary system is also modelled as a string under tensile force suffering a moving upward force, and relation between wave propagation velocity in the string and moving velocity of the upward force are analyzed in Manabe's book [14]. According to the book, following results are demonstrated by the string and moving force model; a large displacement occur at the contact point on the string as the velocity of the moving force approaches to the velocity of wave propagation of the string; when the moving force exceeded the wave propagation velocity, no forward wave propagates and regressive wave with very large amplitude will be generated. Actually, in the real field of rail industry, increasing tensile force in the catenary is widely conducted in case of speedup of vehicles.

To improve the performance of pantograph, efforts to know the contact force between pantograph and catenary [15, 16] or to optimize the shape of pantograph head [17] have been carried out.

The problem of corrugation (periodical wear or undulating wear, see Fig. 5) of catenary has also long been research topics. Corrugation occurs not only high-speed railway but also conventional line, and this problem leads to contact loss. Manabe [19] has been trying to approach to this problem in terms of wave propagation. He modelled a catenary as an Euler beam excited by two moving forces representing pantographs. Using the model, he showed interaction of the waves, which is generated by the moving forces, is strongly relating to the growth of the corrugation in the catenary.

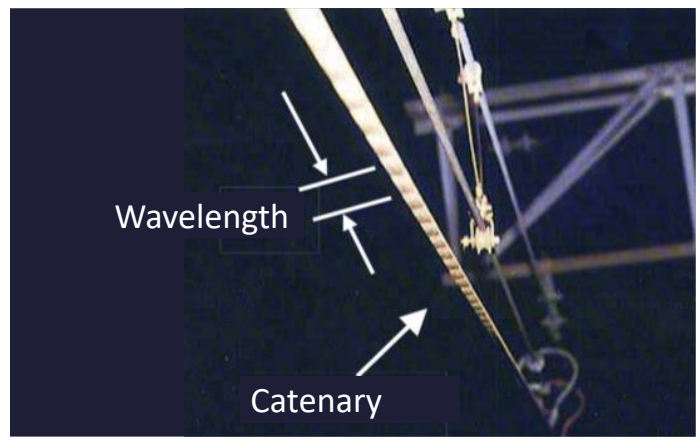

Figure 5. Example of corrugation of catenary [18] 
The corrugation problem is also important in the railwheel system. According to Manabe's book [14], more than 1000 research papers have been published on the topic of rail corrugation. Manabe also applied his wave interaction theory to the rail corrugation growing mechanism [20,21].

\subsection{Aerodynamic interaction to the vehicles}

As the disturbance input acting on the railway vehicle relating to the vehicle dynamics, aerodynamic forces are necessary to be taken into consideration under certain conditions; e.g. strong side wind and aerodynamic force fluctuation during train passage or running in tunnel. The influence of strong side wind will be taken up in sub-section 3.1 in this paper, so the research relating aerodynamic force fluctuation is described here.

As the speed of a vehicle becomes higher, aerodynamic force also increases greatly. As the aerodynamic interaction to the vehicle dynamics, the problem of lateral vibration in tunnel has been received much interest in Japan from the view of ride comfort. Fujimoto et al. [22] revealed from the running test data of a Shinkansen that the lateral vibration of tail car becomes larger than the others in tunnel. They also conducted vehicle dynamics numerical simulation focusing on the relation of tail car lateral vibration and hunting motion, and proposed inter-car yaw damper to reduce tail car's vibration. The inter-car yaw dampers are widely used in Shinkansen and express trains in Japan.

Suzuki et al. studied the aerodynamic force fluctuation from the aspect of experimental and computational fluid dynamics [23, 24]. They proposed to change external parts attached to carbody such as pantograph covers, bogie side covers, etc. to reduce unsteady aerodynamic force acting on the vehicle in tunnel [25]. Sakuma et al. also conducted theoretical [26] and experimental [27] studies about aerodynamic force problem of high-speed trains in tunnel.

\subsection{Application of control techniques}

The demand for the ride comfort of passengers has been getting higher than ever. In addition, as the increase of vehicle speed, to maintain good ride quality by adjusting suspension parameters in the bogie is getting harder. For example, lateral vibration of a high-speed vehicle is mainly caused by long wavelength track irregularity in open section; on the other hand, aerodynamic excitation force acting directly to the carbody is major cause of disturbance in tunnel section. Lateral connection between bogie and carbody should be weak to reduce excitation from track; in contrast it is favorable to connect carbody tightly with bogies to reduce the effect by aerodynamic excitation: that is, parameter settings of lateral suspension for open and tunnel sections contradict each other.

To solve problems under such conflicting situation, control techniques are applied in the suspension system of railway vehicles. Sasaki et al. proposed to apply variable damper in lateral connection between bogie and car body

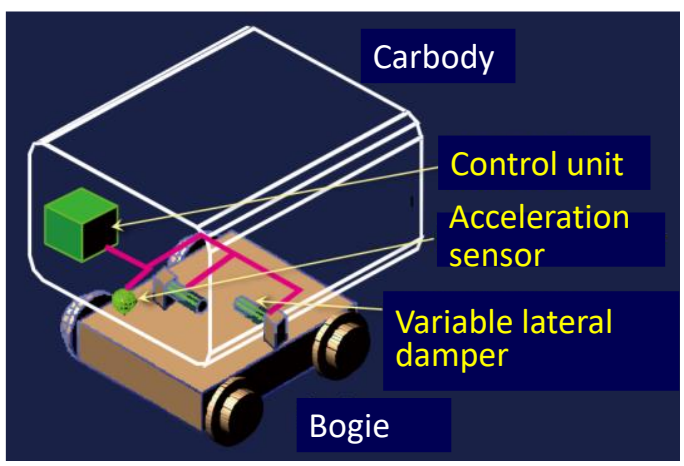

Figure 6. Schematic illustration of lateral semi-active suspension [30]

$[28,29]$. Figure 6 illustrates the lateral semi-active suspension system. The variable damper can change its damping coefficient electrically. This system is called semiactive suspension system since no active force is applied. The semi-active suspension has been used many of Shinkansen and some limited express trains in Japan.

In the beginning of this century, active suspension system was also put into practical use in Japan. The active suspension system uses hydric, pneumatic or electric actuators to apply control force. Active suspensions with pneumatic actuators are firstly used in Shinkansen and electro mechanical actuator (EMA) has recently been getting higher share [31].

Above mentioned semi-active and active suspensions are used mainly to reduce lateral vibration in lateral direction. The concept to apply variable dampers in the vertical suspension was proposed by Sugahara et al. [32] and has been used in some cruise trains running on conventional lines [33].

To shorten traveling time, it is important not only improvement of maximum speed but also speedup in curves, particularly for conventional lines through mountainside. Tilting trains, which have tilting mechanism of carbody to compensate for the shortage of cant when speed-up on sharp curves, are introduced for such purpose; in early times, natural pendulum type mechanisms using centrifugal force itself for tilting action were applied to commercial trains in Japan. Although the natural pendulum type of tilting trains contributed to increase speed in curved sections, it was found that they had matters to induce some passengers' comfort in curved section [36, 37] and high-performance actuator $[38,39]$ with good response to the tilting command are both important in improving performance and ride quality of tilting trains. motion sickness. This was considered caused by the delay of tilting motion at the entry and exit of a curve due to mechanical non-ideality such as friction. To improve the tilting performance and ride comfort, control techniques are used in recent tilting systems [34, 35]. It should be also noted that development of control law to consider passengers'

Recently, air-spring inclination control systems have been widely applied including Shinkansen in Japan as tilting mechanism. By using this system, the tilting angle of 
carbody is limited usually within 2 degrees which is lesser than the above mentioned system with tilting beam (more than 5 degrees of tilting angle is possible); however it needs only a little additional parts in implementation to a vehicle and less maintenance costs [40].

\section{Safety Assessments and Ride Comfort Evaluation}

\subsection{Derailment and overturn}

As shown in Fig.7, the force acting at the contact area of a wheel and a rail in the cross section of the rail can be expressed by vertical and lateral components. They are usually denoted $P$ and $Q$, respectively in Japan, in which the vertical force $P$ is called wheel load. If the wheel load becomes small and/or lateral force becomes large, the risk of derailment will increase, therefore, the ratio $Q / P$ can be used to evaluate safety margin against derailment. The ratio is called the derailment quotient. (Note that the symbols $Y$ and $Q$ respectively are traditionally used for lateral force and wheel load in Europe, so the derailment quotient is expressed as $Y / Q$ there; while in North America the quotient is often described as $L / V$.) Running tests to measure $P$ and $Q$ using actual vehicle are necessarily conducted in order to confirm sufficiently small derailment quotient when; a new type of vehicles or bogies are developed; speedup of existing vehicles is conducted; or a new line has been constructed. These values are measured using special wheels in which strain gauges are installed in the web of the wheels.

As the vehicle running speed increase, wheel load fluctuation tend to be larger and its frequency becomes higher. Exact evaluation of the derailment quotient under such high-frequency fluctuation condition is needed to promise the running safety of Shinkansen vehicles. Ishida et al. proposed the continuous measurement method of the derailment quotient valid at high speed [41, 42], and it is used widely in Japan.

Derailment assessment is also important at low speed since the risk of flange climb exists in sharp curve [43, 44]. To clarify more detailed derailment phenomena at low speed on sharp curves was conducted and a new assessment levels against derailment on curved track has been proposed [44].

Strong side wind may cause the overturn of a vehicle. In Japan, the critical wind speed of overturning proposed by Kunieda [45] is used to evaluate the safety of vehicle running under strong side wind. It is defined as the wind speed when the windward wheel load becomes zero by solving the equation of static balance of external forces acting on the vehicle. Hibino et al. proposed revised version of the formula to include detailed effects of bogie parts and aerodynamic forces [46, 47].

Stability assessment against extremely large external input such as by earthquake is important in Japan. Miyamoto et al. built numerical model to simulate the dynamic response of running vehicles due to earthquake [48, 49]. They also conducted a full-scale experiment of a bogie under

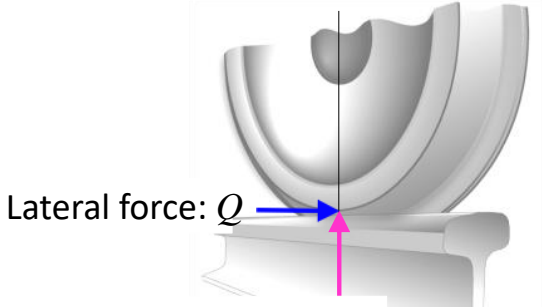

Wheel load: $P$

Figure 7. The forces acting in the contact area of a wheel and the rail

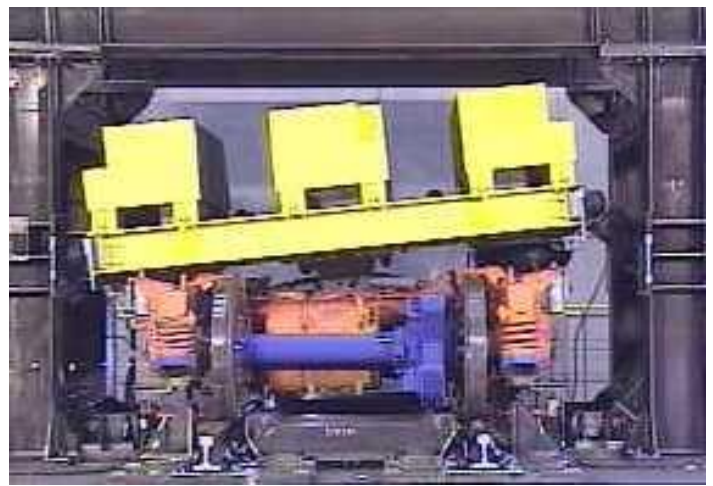

Figure 8. Full-scale shaking experiment of a bogie

large amplitude track vibration as shown in Fig. 8 and compared with the numerical results [50].

\subsection{Ride comfort}

The riding comfort of railway vehicles is relating many factors such as vibration, noise, smell, temperature, humidity, seat design, etc. However, in the aspect of vehicle dynamics, ride comfort evaluation is based on the vibration acceleration measured on the floor (or sometimes on the seat) of running vehicles.

The international standard ISO 2631 [51] is widely referred as the method for evaluating the effect of vibration on human body. On the other hand, in Japan, the riding comfort coefficient and the ride comfort level have been applied to evaluate ride comfort of railway vehicles [52]. Both of them were determined by Japan National Railways (JNR) and are used for more than 35 years without any modification.

Figure 9 shows the diagram used for the ride comfort evaluation based on the ride comfort coefficient. The peak value of acceleration time series measured in the selected test section is plotted versus its frequency on the diagram and the degree of riding comfort is evaluated according to the position of the plot in five ranks. The evaluation diagram is defined for each acceleration direction. This method has the merit to be able to obtain information about frequency together with acceleration amplitude; however the process is difficult to be automated. 


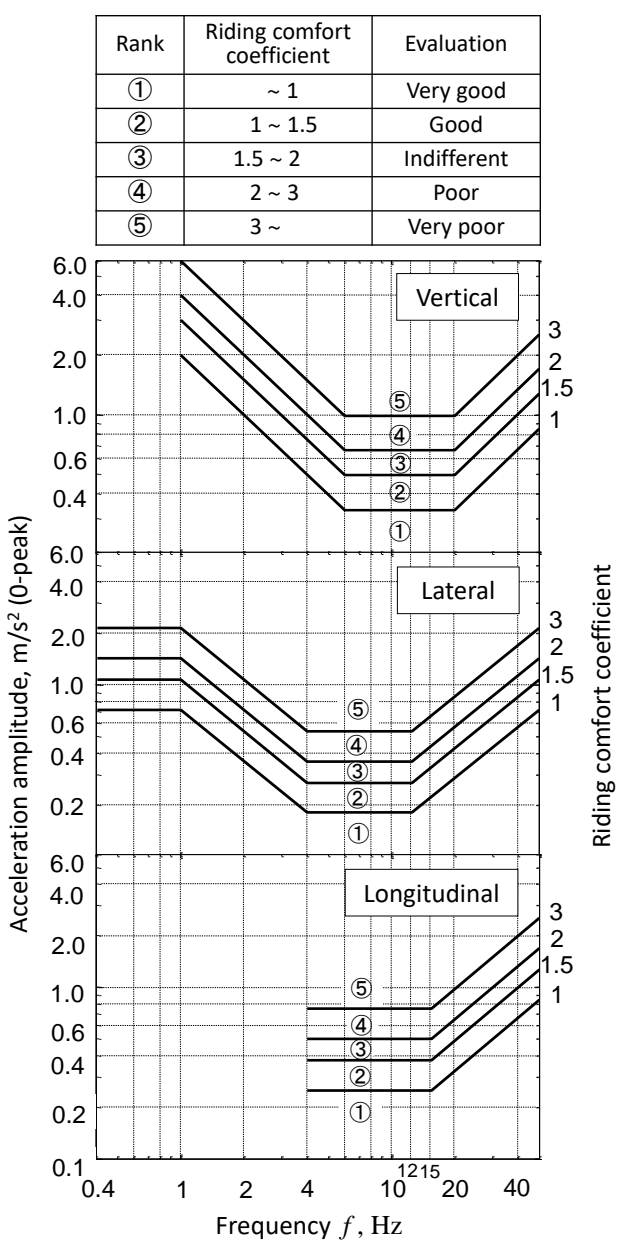

Figure 9. Diagram for the riding comfort coefficient and the ranks of evaluation

\begin{tabular}{|c|c|c|}
\hline Rank & $\begin{array}{c}\text { Riding comfort level } \\
{[\mathrm{dB}]}\end{array}$ & Evaluation \\
\cline { 1 - 2 }$(1)$ & $\mathrm{RCL}<83$ & \multirow{2}{*}{$\begin{array}{c}\text { Good } \\
\uparrow\end{array}$} \\
\cline { 1 - 2 }$(2)$ & $83 \leqq \mathrm{RCL}<88$ & \multirow{1}{}{} \\
\cline { 1 - 2 }$(3)$ & $88 \leqq \mathrm{RCL}<93$ & $\downarrow$ \\
\cline { 1 - 2 }$(4)$ & $93 \leqq \mathrm{RCL}<98$ & \multirow{2}{*}{ Poor } \\
\hline (5) & $98 \leqq \mathrm{RCL}$ & \\
\hline
\end{tabular}

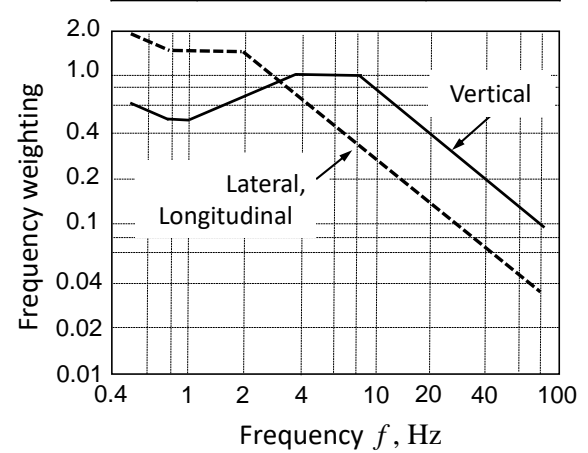

Figure 10. Frequency weightings for the evaluation of ride comfort level and the ranks of evaluation

The ride comfort level ( $\mathrm{RCL}$, in $\mathrm{dB})$ is defined as,

$$
\begin{gathered}
\mathrm{RCL}=20 \log _{10}\left(\frac{A_{\mathrm{w}}}{A_{0}}\right) \\
A_{\mathrm{w}}=\sqrt{\frac{1}{T} \int_{0}^{T} a_{\mathrm{w}}{ }^{2}(t) d t}
\end{gathered}
$$

where $A_{\mathrm{w}}$ is the root mean square (RMS) value of weighted acceleration $a_{\mathrm{w}}(t)$ which is obtained by applying frequency weighting shown in Fig. 10 to the measured acceleration, and $A_{0}$ is the reference acceleration $\left(=10^{-5} \mathrm{~m} / \mathrm{s}^{2}\right)$. The frequency weighting curves represent equivalent sensibility contours, which are originally based on the ISO 2631: 1974 with some modification by JNR. They are considered to reflect human sensitivity for vibration acceleration according to frequency. The evaluation duration $T$ of the RMS value is normally set as $T=3 \pm 2 \mathrm{~min}$, and five ranks of ride comfort are defined alike the riding comfort coefficient. The RCL value can be easily calculated using computers, though, the information about frequency is lost.

These ride comfort evaluations are mainly applied for the vehicles running at constant speed on a straight section. There are also evaluation criteria for the other running situation; e.g. stationary lateral acceleration at curved section; jerk (changing ratio of acceleration) in transition curves; roll motion of tilt trains; and longitudinal acceleration at accelerating or braking of vehicles [52].

\section{Elastic Vibrations of Carbody}

\subsection{Characteristics of elastic vibrations of carbodies}

Due to weight reduction and structural simplification of recent railway vehicles, elastic vibrations of carbody tend to become conspicuous. It is known that such elastic vibrations in vertical direction often occur in the high sensitivity frequency range for human. Figure 11 shows the power spectral density (PSD) measured at the center of floor of a Shinkansen running at $300 \mathrm{~km} / \mathrm{h}$ [53]. The peak around 1-2 $\mathrm{Hz}$ is due to rigid body vibrations and the sharp peak around $8.5 \mathrm{~Hz}$ corresponds to the elastic vibration. It can be understood by considering the human sensitivity for vertical

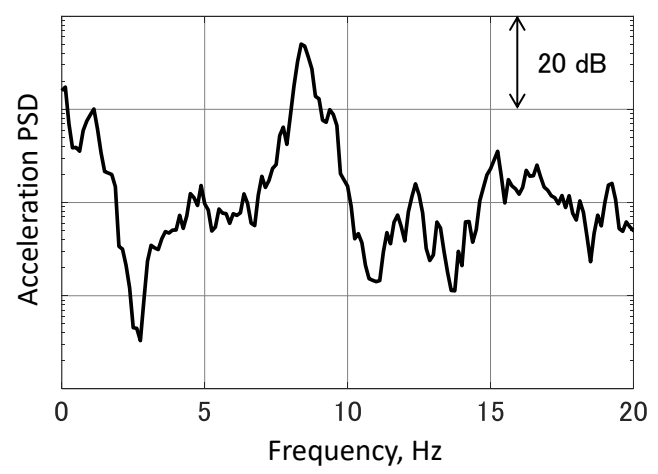

Figure 11. Example of acceleration PSD measured at the center of floor of a Shinkansen. (Running at $300 \mathrm{~km} / \mathrm{h}$.) 
acceleration shown in Fig. 10 that the carbody elastic vibration has certain impact on the ride comfort. Therefore, it is important to reduce or suppress those elastic vibrations to improve ride comfort of a vehicle. The first step to take appropriate measure is to know detailed modal vibration characteristics of carbody [53-55].

The characteristics of mode shapes are different according to the body construction mainly by the material of carbody shell. In Japan, aluminum alloys and stainless steels are major materials for carbody shells. The mode shapes of actual vehicles obtained by experimental modal analysis [54] for a Shinkansen with aluminum alloy body shell and a commuter vehicle with stainless steel body shell are illustrated in Figs. 12 and 13, respectively [53]. We can see that the characteristics of elastic vibration modes are different. Recent aluminum alloy carbody shells are constructed by continuous welding of long hollow extruded members; therefore, the mode shapes have tendency to show the roof and floor deforms similar manner, and some of them looked like that of a simple free-supported beam. For the case of stainless steel carbody, each part of the carbody shell is constructed separately into a panel and each panel is connected discretely using small joint plates called gusset plates, so each surface of carbody tends to vibrate independently.

\subsection{Modelling for analyzing carbody elastic vibrations}

As the mathematical treatment of the carbody elastic vibration, beam models in which the carbody is modelled as
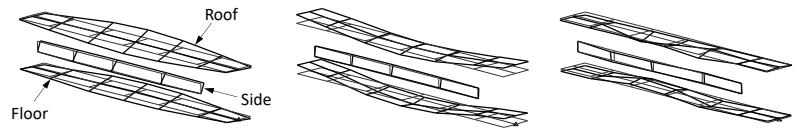

(a) Diagonal distortion, $10.0 \mathrm{~Hz}$ (b) 1 st bending, $10.1 \mathrm{~Hz}$ (c) 2nd bending, $12.7 \mathrm{~Hz}$

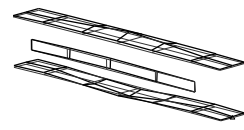

(d) Breathing, $13.6 \mathrm{~Hz}$

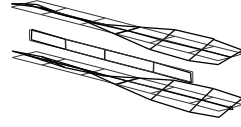

(e) Twisting, $16.1 \mathrm{~Hz}$
Figure 12. Mode shapes and their natural frequencies of a Shinkansen vehicle carbody measured in a stationary excitation test. (Aluminum alloy carbody shell.)

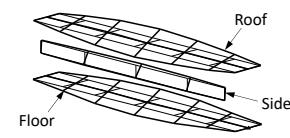

(a) Diagonal distortion, $7.2 \mathrm{~Hz}$

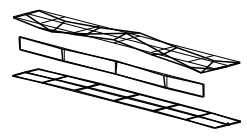

(d) Roof 3rd, $10.4 \mathrm{~Hz}$

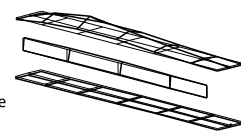

(b) Roof 1st, $8.2 \mathrm{~Hz}$

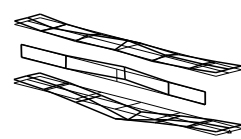

(e) Breathing, $10.9 \mathrm{~Hz}$

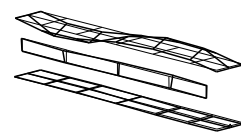

(c) Roof 2nd, $9.1 \mathrm{~Hz}$

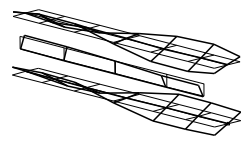

(f) Twisting, $12.7 \mathrm{~Hz}$
Figure 13. Mode shapes and their natural frequencies of a commuter-type vehicle carbody measured in a stationary excitation test. (Stainless-steel carbody shell.) a simple free-supported (uniform) beam have been used traditionally [e.g. 56-58]. This analytical approach is valid for the case that the objective vehicle has the bending mode similar to the beam, such as Fig. 12(b), and only for the first mode of bending of the beam. Although this model seems too simple to express actual vehicles, it is often used even now $[59,60]$. As pointed out in ref. [61], the bending mode of carbody is excited by track irregularity not only through vertical suspension (such as air springs that support carbody on the bogie frames), but also through longitudinal connecting members between bogie and carbody such as traction links or yaw dampers. Although many of the beam models are not taken into account of such longitudinal connection, the author considers the effect must be included since the carbody response may be changed largely due to the longitudinal coupling [63].

In order to express the detailed vibration characteristics including many complicated modes like Figs 12 and 13, finite element (FE) models are the most powerful tool, and many commercial software are available now. A number of research are done by using FE models [e.g. 63-65].

A numerical model should be validated by measured data, and in many case, some iterative effort to modify and/or adjust the numerical model are needed. This modification process is called correlation or model update. As a numerical model becomes detailed, the difficulty of model update usually increases. Tomioka et al. [66] proposed a simple model considering the carbody as a three-dimensional (3D) structure consisting of plates and beams as shown in Fig. 14.

The condition to connect these components (plates and beams) is satisfied by introducing artificial springs at their joints. The biggest merit of this model is that the degree of freedom of the model is quite small (less than 1,000) in comparison to FE models (usually more than 500,000); and therefore numerical optimization algorithms such as genetic algorithm (GA) can be applied in model update process [67]. This simple 3D vibration model is called the Box-type model.

\subsection{Measures for the elastic vibrations of carbody}

Several efforts have been carried out to reduce elastic vibration for a long time in Japan. As mentioned former, elastic vibration of carbody is often modelled as a first mode

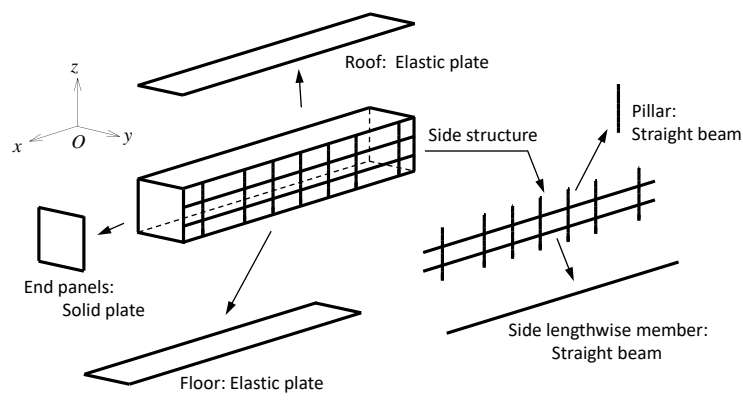

Figure 14. The three-dimensional analytical model for elastic vibrations of railway vehicle carbody as combination of plates and beams 
of bending of an elastically supported beam, the counter measures are also studied by using such analysis model. Suzuki, et al. proposed to apply damping layer consist of viscoelastic and constraint layers [68]. In the study, the carbody was modelled as a partially layered beam to investigate the effect of damping layer, and it was found that the optimum length exists for the damping layer. The results were validated by running tests of an actual vehicle, and the damping layer was put into practical use of a commercial Shinkansen vehicle.

The idea to use underfloor equipment as dynamic vibration absorber (DVA) is also traditionally examined. Ishikawa and Sato [69] conducted a running test by applying elastically supported mass which imitated underfloor equipment and showed the reduction of carbody elastic vibration. However, there is no actual example to utilize under floor equipment as DVA in the trains for commercial passenger service in Japan. By the author's view, the one reason of this is that railway operating companies in Japan don't want to use equipment as moving mass; and the other reason is the difficulty to adjust the natural frequency of supported equipment to the target frequency of the carbody vibration. In addition, as shown in sub-section 4.1, more than one natural mode affect ride comfort in many cases. Recently, there are some trials to apply underfloor equipment to reduce multiple modes of carbody elastic vibration. Aida, et al. [70] proposed to support underfloor equipment with high-damping material having natural frequency less than that of the lowest carbody elastic vibration. By this treatment, they showed multi-modal vibration reduction can be realized without any frequency adjustment of DVA by the excitation tests for a 1:1 scale test vehicle on the roller rig. Looking into outside of Japan, Gong et al. [71] also studied to use several equipment underneath floor and on the roof to use DVAs for different elastic modes of vibration through numerical study using FE analysis.

As an interesting usage of DVA against elastic vibration of carbody bending mode, Tomioka and Takigami proposed to utilize the longitudinal motion of the bogie frames [62]. They derived the condition to tune the natural frequency of the longitudinal vibration of bogie frames to the target carbody bending frequency theoretically, and validated the formula through excitation test on the roller rig and running test on a commercial line of a Shinkansen. This formula is used in the bogie design for Shinkansen.

The studies on vibration reduction measure to consider the 3D deformation of carbody, Akiyama et al. [72] proposed to apply active mass dampers (AMDs) to reduce not only the bending mode but also the elastic mode with the diagonal distortion of carbody cross section. They conducted numerical analysis using their simple 3D vibration model (the Box-type model), roller rig test for 1:1 scale test vehicle, and also running test of a Shinkansen.

Structural design of carbody shells for railway vehicle is generally based on the concept of semi-monocoque structure, in which the outer thin panel of carbody shell plays main role on the strength and rigidity. Therefore, when improving carbody rigidity considering elastic vibration suppression, it needs modification of outer shell structure and there are many difficulty, especially for the existing vehicles. Takigami, et al. proposed to use non-structural members such as frames inside carbody [73, 74]. Their effort on this concept has been sophisticated by utilizing other lighter weight inner members such as handrails [75], and it is applied in the most recent commuter type vehicles as the interior roll-bar which intend to not only improving carbody rigidity but also crashworthiness against side impact.

\subsection{Influence of passengers on the carbody vibrations}

As the weight of vehicles reduce, the weight ratio of passengers to carbody increases; e.g. the weights of typical commuter vehicles in Japan are around 13 - 18 tonne in the case of trailer cars, while a full car load of passengers (approx. 160 passengers) weighs more than 9 tonne. If the passengers act as such a big mass loading on a vehicle, vibration characteristics of carbody shall be influenced greatly.

The effect of passengers on vehicle dynamics is usually taken into account as mass distributed on the floor. Designers design the carbody so that it can have higher natural frequencies (as far as possible, exceeding $8 \mathrm{~Hz}$ ) under a full-capacity passenger load.

Kaneda et al. [76], however, reported that the change of natural frequencies was small in contrast with the relatively large reduction of vibration amplitude of the carbody in case passengers were boarding, as a result of excitation tests using a partial mock-up of a carbody. This suggest that onboard passengers act as damping elements upon the carbody elastic vibrations rather than additional mass.

Tomioka et al. studied the effect of passengers on the elastic vibrations using several types of actual vehicles [77, 78]. Figure 15(a) shows the acceleration PSD measured in a running test of a Shinkansen during $270 \mathrm{~km} / \mathrm{h}$ for different numbers of passengers [77]. The peak observed around 10.5 $\mathrm{Hz}$ corresponds to the elastic vibration of carbody. It can be seen that the peak value reduces according to the increase of the number of passengers, whereas the change of peak frequency is very small. Figure 15(b) shows the comparison for different loadings; that is, for the loading cases with 51 passengers and $5100 \mathrm{~kg}$ of iron blocks on the floor. It is clear that the change of the peak around $10.5 \mathrm{~Hz}$ has different tendencies. From both figures, it has been found that passengers on the vehicles show the effect as not pure mass rather damping. Figure 16 shows the excitation test result for a commuter type vehicle on the roller rig [78]. Large vibration reductions are observed for at least two peaks around $7 \mathrm{~Hz}$ and $11 \mathrm{~Hz}$. 


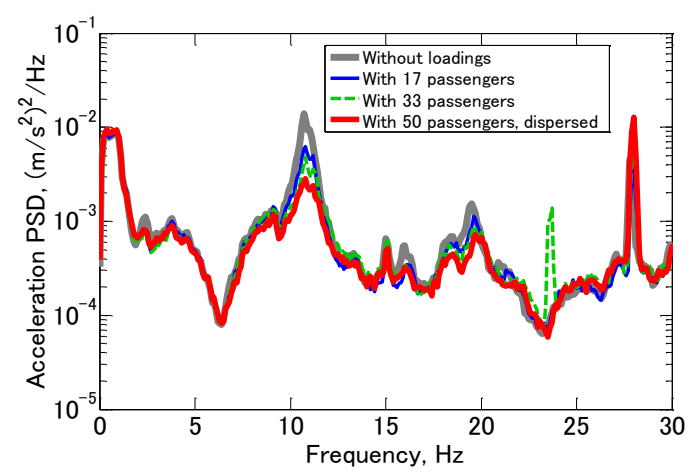

(a) Effect of the number of passengers.

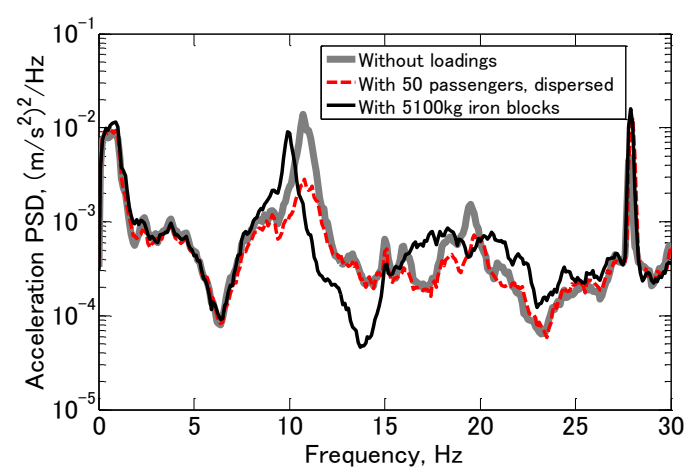

(b) Comparison of PSD loaded with 50 passengers and $5100 \mathrm{~kg}$ of iron blocks on the floor.

Figure 15. Acceleration PSDs of a Shinkansen measured during running at $270 \mathrm{~km} / \mathrm{h}$. (At longitudinal center, window side on the floor.)

The large and multi-modal vibration reduction effect by human body observed in actual vehicles suggests the possibilities to realize some new effective damping devises by mimicking the passengers' motion correctly. Some trials have been already conducted by the authors [70, 78-80].

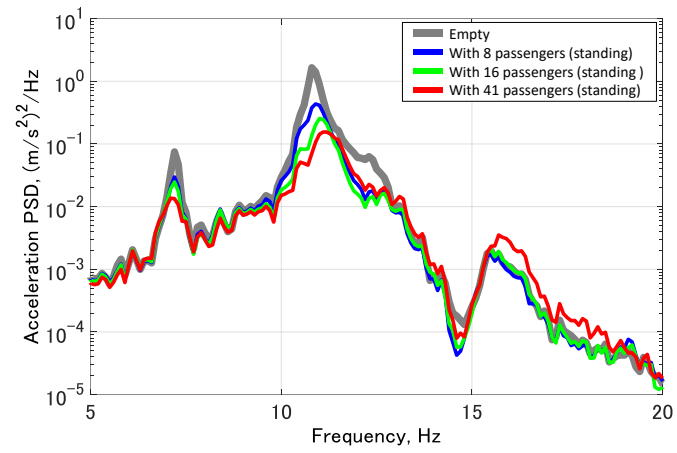

Figure 16. Acceleration PSDs of a commuter type vehicle measured by excitation test on the roller rig. (At longitudinal center, window side on the floor. All-axle simultaneous excitation,)

\section{Conclusions}

Engineering research subjects relating to the dynamics of railway vehicles have been surveyed in this paper. The focuses are particularly on the research works from Japan.

The researches concerning to the motion of wheelset; pantograph-catenary interaction; aerodynamic relating problems on the vehicle; and application of control techniques have been introduced firstly as the most distinctive subjects of railway vehicle dynamics.

The safety assessment and ride comfort evaluation have been dealt with, too. Those are important research topics on railway dynamics as public transportation system.

The subject concerning to carbody elastic vibration, which is important relating to ride comfort, has been described after that. The effect of passengers on the elastic vibration of carbody has been introduced as the interesting (and something surprising) topic.

Since this article assumes researchers outside the railway industry as the readers, the descriptions may be insufficient for the specialists in this field. For such readers, more detailed review is available by Miyamoto and Suda [81] about the research and development of advanced railway vehicle technologies in Japan.

The author thinks dynamics of railway vehicle is very interesting target of research, especially for the researchers in mechanical engineering. It is great pleasure for him if this survey can give some help or be an informative guide for researchers to take interests on railway vehicles.

\section{References}

[1] Wickens, A.H., Fundamentals of Rail Vehicle Dynamics, CRC Press, 2003.

[2] Iwnicki, S. (ed), Handbook of Railway Vehicle Dynamics, CRC Press, 2006.

[3] Klingel, Uber den Lauf der Eisenbahnwagen auf gerader Bahn, Organ fur die Fortschritte des Eisenbahnwesens in technischer Beziehung, Neue Folge, 20, 1883, pp.113-123.

[4] Matsudaira, T., Shimmy of Axle with a Pair of Wheels, Bulletin of the Railway Technical Laboratory Journal of railway engineering research, 9, 1952, pp. 16-26 [in Japanese].

[5] Matsudaira, T., Nosing of 2-axle Railway Cars and its Prevention: 1st Reports, Theory, Transactions of the Japan Society of Mechanical Engineers, 19, 1953, pp. 139-146 [in Japanese]. (DOI https://doi.org/ 10.1299/kikai1938.19.87_139)

[6] Matsudaira, T., Nosing of 2-axle Railway Cars and its Prevention: 2nd Report, Model Experiment, Transactions of the Japan Society of Mechanical Engineers, 19, 1953, pp. 146-153 [in Japanese]. (DOI https://doi.org/10.1299/kikai1938.19.87_146)

[7] Matsudaira, T., Nosing of 2-axle Railway Cars and its Prevention: 3rd Report, Application to Actual Cars, Transactions of the Japan Society of Mechanical Engineers, 19, 1953, pp. 154-157 [in Japanese]. (DOI https://doi.org/10.1299/kikai1938.19.87_154)

[8] Matsudaira, T., Hunting Problem of High-Speed Railway Vehicles with Special Reference to Bogie Design for the New Tokaido Line", Proceedings of the Institution of Mechanical Engineers Part 3F, 180, 1965, pp. 55-66.

[9] Suda, Y., High Speed Stability and Curving Performance of Longitudinally Unsymmetric Trucks with Semi-active Control, Vehicle System Dynamics, 23, 1994, pp. 29-52. 
[10] Sato, E., Kobayashi, H., Tezuka, K., Okamoto, I., Kakinuma, H. and Tamaoki, T., Lateral Force during Curve Negotiation of Forced Steering Bogies, Quarterly Report of RTRI, 44, 2003, pp.8-14. (DOI https://doi.org/10.2219/rtriqr.44.8)

[11] Togami, Y.,Goto, R., Ogino, T., Shikata, K., Toide, T., Mizuno, M. and Shimokawa, Y., Development of the New Concept Steering Bogie, Journal of Mechanical Systems for Transportation and Logistics, 6, 2013, pp.124-132. (DOI https://doi.org/10.1299/ jmtl.6.124)

[12] Shimokawa, Y. and Mizuno, M., Development of the New Concept Steering Bogie, Nippon Steel \& Sumitomo Metal Technical Report, 105, 2013, pp.41-47. (http://www.nssmc.com/en/tech/report/nssmc/pdf/ 105-08.pdf)

[13] Shibata, H., Problems on the Current Collection of an Electric Rolling Stock at High Speeds, Journal of the Society of Mechanical Engineers, 63, 1960, pp.1118-1128 [in Japanese].

[14] Manabe, K., Wave Motions and Vibrations in Railway Systems [in Japanese], Kotsu Shimbunsya, 2002.

[15] Aboshi, M. and Manabe, K., Analyses of Contact Force Fluctuation between Catenary and Pantograph, Quarterly Report of RTRI, 41, 2000, pp.182-187. (DOI https://doi.org/10.2219/rtriqr.41.182).

[16] Ikeda, M., The Contact Force between Pantograph and Contact Wire -An Estimation Method Using the Inversion Technique, Quarterly Report of RTRI, 41, 2004, pp.80-85. (DOI https://doi.org/10.2219/ rtriqr.45.80)

[17] Ikeda, M., Suzuki, M. and Yoshida, K. Study on Optimization of Panhead Shape Possessing Low Noise and Stable Aerodynamic Characteristics, Quarterly Report of RTRI, 47, 2006, pp.72-77. (DOI https://doi.org/10.2219/rtriqr.47.72)

[18] Koyama, T. and Aboshi, M., Revealing the generating mechanism of contact wire corrugation [in Japanese], Railway Research Review, 719, 2014, pp.8-11. (https://bunken.rtri.or.jp/PDF/cdroms1/0004/2014/0004006120.pdf)

[19] Manabe, K., Dynamic Analysis on the Generating Mechanism of Contact Wire Corrugation, Transactions of the Japan Society of Mechanical Engineers, 66, 2000, pp. 454-459 [in Japanese]. (DOI https://doi.org/10.1299/kikaic.66.454)

[20] Manabe, K., A hypothesis on a wavelength fixing mechanism of rail corrugation, Proceedings of the Institution of Mechanical Engineers Part F, 214, 2000, pp.21-26.

[21] Manabe, K., Verification of Wavelength-Fixing Mechanism for Rail Corrugation Caused by Multiple-Wheel Interaction, Quarterly Report of RTRI, 48, 2007, pp.164-169. (DOI https://doi.org/10.2219/rtriqr.48.164)

[22] Fujimoto, H., Miyamoto, M. and Shimamoto, Y., Lateral Vibration and its Decreasing Measure in the Tail Car of a Shinkansen (Decrease of Tail Car's Vibration with Yaw Damper between Cars), Transactions of the Japan Society of Mechanical Engineers Series C, 59, 1993, pp.1016-1022 [in Japanese]. (DOI https://doi.org/10.1299/kikaic.59.1016)

[23] Suzuki, M. Unsteady Aerodynamic Force Acting on High Speed Trains in Tunnel, Quarterly Report of RTRI, 42, 2001, pp.89-93. (DOI https://doi.org/10.2219/rtriqr.42.89)

[24] Suzuki, M., Ido, A., Sakuma, Y. and Kajiyama, H. Full-Scale Measurement and Numerical Simulation of Flow Around High-Speed Train in Tunnel, Journal of Mechanical Systems for Transportation and Logistics, 1, 2008, pp.281-292. (DOI https://doi.org/10.1299/jmtl.1.281)

[25] Suzuki, M., Nakade, K. and Ido, A. Countermeasures for Reducing Unsteady Aerodynamic Force Acting on High-Speed Train in Tunnel by Use of Modifications of Train Shapes, Journal of Mechanical Systems for Transportation and Logistics, 2, 2009, pp.1-12. (DOI https://doi.org/10.1299/jmtl.2.1)

[26] Sakuma, Y., Paidoussis, M. P., Price, S. and Suzuki, M. Aerodynamic Forces Acting on and Lateral Translational and Rotational Motions of Intermediate Cars Travelling in a Tunnel, Journal of System Design and Dynamics, 2, 2008, pp.240-250.
(DOI https://doi.org/10.1299/ jsdd.2.240)

[27] Sakuma, Y., Suzuki, M., Ido, A. and Kajiyama, H. Measurement of Air Velocity and Pressure Distributions around High-Speed Trains on Board and on the Ground, Journal of Mechanical Systems for Transportation and Logistics, 3, 2010, pp.110-118. (DOI https://doi.org/ 10.1299/jmtl.3.110)

[28] Sasaki, K., Kamoshita, S. and Shimomura, T. Development and Field Results of Semi-Active Suspension High Speed Train. [in Japanese], RTRI report, 10, 1996, pp.25-30

[29] Oishi, T, Hayashi, T., Sasaki, K. and Arai, J. Development of Advanced Semi-Active Suspension System for Shinkansen Vehicles, Proceedings of the International Symposium on Speed-up and Service Technology for Railway and Maglev Systems 2003 (STECH2003), August 19-22.2003, Tokyo, Japan, pp.220-224.

[30] Sasaki, K., Toward More comfortable Shinkansen: Development of semi-active suspensions, Railway Research Review, 73-6, 2016, pp.20-23 [in Japanese]. (https://bunken.rtri.or.jp/PDF/cdroms1/0004/2016/ 0004006506.pdf)

[31] Goto, O. Development of Active Lateral Suspension for Railway Vehicle, Journal of The Society of Instrument and Control Engineers, 56, 2017, pp. 127-130 [in Japanese]. (DOI https://doi.org/ 10.11499/ sicej1.56.127)

[32] Sugahara, Y., Kazato, A., Koganei, R., Sampei, M. and Nakaura, S. Suppression of vertical bending and rigid-body-mode vibration in railway vehicle car body by primary and secondary suspension control: Results of simulations and running tests using Shinkansen vehicle, Proceedings of the Institution of Mechanical Engineers Part F, 223, 2009, pp.517-531.

[33] Sugahara, Y. Development of a Vibration Suppression System of Railway Vehicle Using Variable Vertical Dampers, Journal of The Society of Instrument and Control Engineers, 54, 2015, pp.668-671 [in Japanese]. (DOI https://doi.org/10.11499/sicej1.54.668)

[34] Okamoto, I., Speed-up in Curves, Journal of The Society of Instrument and Control Engineers, 32, 1993, pp.577-581 [in Japanese]. (DOI https://doi.org/10.11499/sicej11962.32.7_577)

[35] Kobayashi, H. Okamoto, I. and Akiyama, Y. The Forced Steering Tilt Truck for Diesel Limited Express, Quarterly Report of RTRI, 41, 2000, pp.16-20. (DOI https://doi.org/10.2219/rtriqr.41.16)

[36] Suzuki, H., Shiroto, H., Tanaka, A., Tezuka, K. and Takai, H., Psychophysical Evaluation of Railway Vibrational Discomfort on Curved Sections, Quarterly Report of RTRI, 41, 2000, pp.106-111. (DOI https://doi.org/10.2219/rtriqr.41.106)

[37] Suzuki, H., Shiroto, H. and Tezuka, K., Effects of Low Frequency Vibration on Train Motion Sickness, Quarterly Report of RTRI, 46, 2005, pp.35-39. (DOI https://doi.org/10.2219/rtriqr.46.35)

[38] Enomoto, M., Kamoshita, S., Kamiyama, M., Sasaki, K., Hamada, T. and Kazato, A., Development of Tilt Control System Using ElectroHydraulic Actuators, Quarterly Report of RTRI, 46, 2005, pp.219-224. (DOI https://doi.org/10.2219/rtriqr.46.219)

[39] Kamoshita, S., Sasaki, K., Kakinuma, H., Sato, I., Sato, Y. and Nakagaki,, S. A Control Method for Hybrid Tilting Systems using Tilting Beams and Air Spring Inclination, Quarterly Report of RTRI, 48, 2007, pp.1-7. (DOI https://doi.org/10.2219/rtriqr.48.1)

[40] Yamada, T. Air Spring Tilting Control System for Rolling Stock, Journal of The Society of Instrument and Control Engineers, 56, 2017, pp.123-126 [in Japanese]. (DOI https://doi.org/10.11499/sicej1.56.123)

[41] Ishida, H. et al., A New Continuous Measuring Method of Wheel/Rail Contact Forces, Quarterly Report of RTRI, 35, 1994, pp.105-111.

[42] Ishida, H., Matsuo, M., Tezuka, K. and Ueki, K., Method of Measuring Wheel and Rail Contact Forces and Derailment Quotients Continuously: Development of a Measuring Device, Transactions of the Japan Society of Mechanical Engineers Series C, 63, 1997, pp.3417-3423 [in Japanese].

(DOI https://doi.org/10.1299/ kikaic.63.3417) 
[43] Accidental Investigation Commission, Report on the Train Derailment at Nakameguro Station on the Tokyo Metro Co. Hibiya Line, October 2000 [in Japanese].

[44] Ishida, H., Miyamoto, T., Maebashi, E., Doi, H., Iida, K. and Furukawa, A., Safety Assessment for Flange Climb Derailment of Trains Running at Low Speeds on Sharp Curves, Quarterly Report of RTRI, 47, 2006, pp.65-71. (DOI https://doi.org/10.2219/rtriqr.47.65)

[45] Kunieda, M., Theoretical Study on the Mechanics of Overturn of Railway Rolling stock, Railway Technical Research Report, 793, 1972, pp.1-15 [in Japanese].

[46] Hibino, Y. and Ishida, H. Static Analysis on Railway Vehicle Overturning under Crosswind, RTRI report, 17, 2003, pp.39-44 [in Japanese].

[47] Hibino, Y., Shimomura, T. and Tanifuji, K. Full-Scale Experiment on the Behavior of a Railway Vehicle being Subjected to Lateral Force, Journal of Mechanical Systems for Transportation and Logistics, 3, 2010, pp.35-43. (DOI https://doi.org/10.1299/jmtl.3.35)

[48] Miyamoto, T., Ishida, H. and Matsuo, M., Running Safety of Railway Vehicle as Earthquake Occurs, Quarterly Report of RTRI, 38, 1997, pp.117-122.

[49] Miyamoto, T., Ishida, H. and Matsuo, M., The Dynamic Behavior of Railway Vehicle during Earthquake : Vehicle Dynamics Simulation on Track Vibrating in Lateral \& Vertical Directions, Transactions of the Japan Society of Mechanical Engineers Series C, 64, 1998, pp. 3928-3935 [in Japanese].

(DOI https://doi.org/10.1299/kikaic.64.3928)

[50] Miyamoto, T., Matsumoto, N., Sogabe, M., Shimomura, T., Nishiyama, Y. and Matsuo, M., Railway Vehicle Dynamic Behavior against Large-Amplitude Track Vibration - A Full-scale Experiment and Numerical Simulation, Quarterly Report of RTRI, 45, 2004, pp.111-115. (DOI https://doi.org/10.2219/rtriqr.45.111)

[51] International Organization for Standardization, ISO 2631-1: Mechanical vibration and shock -- Evaluation of human exposure to whole-body vibration -- Part 1: General requirement, 1997.

[52] Suzuki, H., Research trends on riding comfort evaluation in Japan, Proceedings of the Institution of Mechanical Engineers Part F, 212, 1998, pp.61-72.

[53] Japan Society of Mechanical Engineers (ed), Railway Vehicle Dynamics and Modeling, 2017 [in Japanese].

[54] Tomioka, T., Takigami, T. and Aida, K., Modal Analysis of Railway Vehicle Carbodies Using a Linear Prediction Model, Journal of System Design and Dynamics, 3, 2009, pp. 918-931. (DOI https://doi.org/ 10.1299/jsdd.3.918)

[55] Tomioka, T., Takigami, T. and Aida, K., Modal Vibration Characteristics of Flexural Vibrations in Railway Vehicle Carbodies, Proceedings of the First International Conference on Railway Technology: Research, Development and Maintenance (Railways2012), April 18-20.2012, Las Palmas de Gran Canaria, Spain, Paper No. 33.

[56] Richard, J., Natural Frequencies of Bernoulli-Euler Beams Resting on Two Elastic Supports: Application to Railway Vehicles, Vehicle System Dynamics, 9, 1980, pp.309-326.

[57] Tanifuji, T., An Analysis of the Body-Bending Vibration of a Bogie Vehicle for an Evaluation of the Ride Quality with Deflated Airsprings, Proceedings of the Institution of Mechanical Engineers Part F, 205, 1991, pp.35-42.

[58] Suzuki, Y. and Akutsu, K., Theoretical Analysis of Flexural Vibration of Car Body, Quarterly Report of RTRI, 31, 1990, pp.42-48.

[59] Dumitriu, M., A new passive approach to reducing the carbody vertical bending vibration of railway vehicles, Vehicle System Dynamics, 55, 2017, pp.1787-1806.

[60] Gong, D., Zhou, J. and Sun, W., Passive control of railway vehicle car body flexural vibration by means of underframe dampers, Journal of Mechanical Science and Technology, 31, 2017, pp.555-564.

[61] Eickhoff, B. M., Evans, J. R. and Minnis, A. J., A Review of Modelling Method for Railway Vehicle Suspension Components, Vehicle System Dynamics, 24, 1995, pp.469-496.
[62] Tomioka, T. and Takigami, T., Reduction of bending vibration in railway vehicle carbodies using carbody-bogie dynamic interaction, Vehicle System Dynamics, 48 (Supplement), 2010, pp.467-486.

[63] Carlbom, P.F., Combining MBS with FEM for rail vehicle dynamics analysis, Multibody System Dynamics, 6, 2001, pp.291-300.

[64] Diana, G., Cheli, E., Andrea, C., Corradi, R. and Melzi, S., The development of a numerical model for railway vehicles comfort assessment through comparison with experimental measurements, Vehicle System Dynamics, 38, 2002, pp.165-183.

[65] Ribeiro, D., Calçada, R., Delgado, R., Brehm, M. and Zabel, V., Finite-element model calibration of a railway vehicle based on experimental modal parameters, Vehicle System Dynamics, 51, 2013, pp.821-856.

[66] Tomioka, T., Takigami, T. and Suzuki, Y., Numerical analysis of three-dimensional flexural vibration of railway vehicle car body, Vehicle System Dynamics, 44 (Supplement), 2006, pp. 272-285.

[67] Akiyama, Y., Tomioka, T., Suzuki, Y. and Takigami, T., Parameter Updating of Three-dimensional Vibration Model for Railway Vehicle Carbodies Using Measured Data, Proceedings of the 5th Asian Conference on Multibody Dynamics (ACMD2010), August 23-26. 2010, Kyoto, Japan, Paper No. 63816.

[68] Suzuki, Y., Akutsu, K., Maebashi, E., Sasakura, M. and Tomioka, T., Method for Flexural Vibration Damping of Rolling Stock Carbody, Quarterly Report of RTRI, 38, 1997, pp.123-128.

[69] Ishikawa, R. and Sato, Y., Decrease of vehicle body bending vibration by dynamic damper, Proceedings of the 68th JSME Spring Annual Meeting Vol. C, 1991, pp.531-533 [in Japanese].

[70] Aida, K., Tomioka, T., Takigami, T., Akiyama, Y. and Sato, H., Reduction of Carbody Flexural Vibration by the High-damping Elastic Support of Under-floor Equipment, Quarterly Report of RTRI, 56, 2015, pp.262-267. (DOI https://doi.org/10.2219/rtriqr.56.4_262)

[71] Gong, D., Zhou, J., Sun, W., Sun, Y. and Zhanghui, X., Method of multi-mode vibration control for the carbody of high-speed electric multiple unit trains, Journal of Sound and Vibration, 404, 2017, pp.94111.

[72] Akiyama, Y., Tomioka, T. and Takigami, T., Development of Active Mass Dampers for Reducing Multi-modal Flexural Vibrations of Carbody, Quarterly Report of RTRI, 55, 2014, pp.1-6. (DOI https://doi.org/10.2219/rtriqr.55.1)

[73] Takigami, T., Tomioka, T. and Aida, K., Improving the Rigidity of Railway Vehicle Carbodies Using Non-Structural Members, Quarterly Report of RTRI, 50, 2009, pp.63-69. (DOI https://doi.org/10.2219/ rtriqr.50.63)

[74] Takigami, T., Tomioka, T. and Aida, K., Improving the Rigidity of Railway Vehicle Carbodies Using Inner Sub-Frames, Transactions of the Japan Society of Mechanical Engineers Series C, 76, 2010, pp.1115-1123 [in Japanese]. (DOI https://doi.org/10.1299/kikaic.76.1115)

[75] Imaoka, N., Improving the rigidity of Carbodies and Ride Comfort by Interior Roll-bar [in Japanese], J-TREC Technical Review, 2, 2013, pp.26-33. (https://www.j-trec.co.jp/company/070/02/jtr02.pdf)

[76] Kaneda, T., Kobayashi, H., Oda, M. and Akiyama, S., Study of human body effect to vibration of railway vehicle body, Proceedings of the 75th annual meetings of JSME Kansai-section No.004-1, March; 2000, pp.2.29-2.30 [in Japanese].

[77] Tomioka, T. and Takigami, T., Experimental and numerical study on the effect due to passengers on flexural vibrations in railway vehicle carbodies, Journal of Sound and Vibration, 343, 2015, pp.1-19.

[78] Tomioka, T., Takigami, T. and Aida, K., Experimental investigations on the damping effect due to passengers on flexural vibrations of railway vehicle carbody and basic studies on the mimicry of the effect with simple substitutions, Vehicle System Dynamics, 55, 2017, pp.995-1011.

[79] Tomioka, T., Tachikawa, S. and Akiyama, Y., Development of torusshaped elastic body as a vibration absorber for flexural vibration in railway vehicle carbody and its experimental validation using 
commuter-type vehicle, Mechanical Engineering Journal, 4, 2017, p.16-00467. (DOI https://doi.org/10.1299/mej.16-00467)

[80] Tomioka, T., Tachikawa, S., Akiyama, Y. and Aida, K., Reduction of flexural vibration of railway vehicle carbody by using elastic torus (Validation of vibration reduction effect using actual railway vehicle and numerical investigations on the vibration reduction mechanism), Transactions of the JSME, 83, 2017, p.16-00342 [in Japanese].

(DOI https://doi.org/10.1299/transjsme.16-00342)

[81] Miyamoto, M. and Suda, Y., Recent Research and Development on Advanced Technologies of High-Speed Railways in Japan, Vehicle System Dynamics, 40, 2003, pp.55-99. 